\title{
THE DYNAMIC COMPLEXITIES OF METAPHOR INTERPRETATION
}

\section{(As complexidades dinâmicas da interpretação de metáforas)}

\author{
Raymond W. GiBBS JR \\ (University of California, Santa Cruz - U.S.A)
}

\begin{abstract}
Metaphor interpretation takes cognitive effort and produces some complex set of cognitive effects. Although most metaphor scholars assume that there are definitive ways for studying metaphor effort and effects, there are various methodological problems associated with specifying metaphorical meanings and the ways that people generally come to understand these meanings. My claim is that both metaphoric meaning and metaphor interpretation is fundamentally indeterminate. Nonetheless, there are a wide range of factors that shape the effort put into understanding a metaphor and the particular reffects that arise from this experience. These personal, linguistic, and socio-cultural factors are sometimes acknowledged by metaphor scholars, but we need to examine the complex ways these factors interact to systematically characterize people's metaphorical experiences.
\end{abstract}

Key-words: metaphor interpretation; cognitive effort; metaphor comprehension.

Resumo: A interpretação de metáforas requer esforço cognitivo e produz alguns conjuntos complexos de efeitos cognitivos. Embora a maioria dos estudiosos da metáfora acredite que há maneiras específicas para se estudar o esforço envolvido na compreensão metafórica e seus efeitos, existem vários problemas metodológicos associados com a especificação de significados metafóricos e quanto aos modos as pessoas chegam a entender tais significados. Minha proposta é a de que tanto o significado metafórico quanto a interpretação metafórica é fundamentalmente indeterminada. Contudo, há uma variedade considerável de fatores que moldam o esforço que é colocado para se entender a metáfora e os efeitos específicos que resultam dessa experiência. Tais fatores de natureza pessoal, linguística e sócio-cultural são às vezes reconhecidos pelos estudiosos da metáfora; contudo, necessitamos examinar os modos complexos como esses fatores interagem para caracterizar sistematicamente as experiências das pessoas com metáforas.

Palavras-chave: interpretação de metáfora; esforço cognitivo; compreensão de metáforas. 


\section{THE DYNAMIC COMPLEXITIES OF METAPHOR INTERPRETATION}

It is always a special pleasure for me to visit Brazil, as it is one of the most beautiful countries in the world. Before my last trip to the "Metaphor and Thought III" conference in Fortaleza, I came upon a web site describing Fortaleza as the "Blonde bride of the sun." This lovely phrase, like many poetic metaphors, evokes varied impressions and images. But what does this metaphoric description of Fortaleza really mean? I asked a group of university students in California to write down their interpretations of "Fortaleza is the blonde bride of the sun," and not surprisingly received a variety of responses. Consider a few of these:

"Fortaleza is young, vibrant, and cherished. A special place."

"Fortaleza is warm, being associated with the sun/husband, yet is especially beautiful and charming because she is not only married to the sun but is a blonde bride which makes her especially lovely and attractive. Everyday in this city must be like a wedding day."

"Because the sun is the omnipresent power, the blonde bride is less dominating, but more alluring, than the sun. Fortaleza is not forceful or blazing, but is more feminine, and is more welcoming to people."

"The blonde bride is the youthful, precious, warm, yet not hot, counterpart to her older, established sun husband. It suggests a city that is inviting, also sunny (blonde), yet not corrupted."

It may be impossible to determine which, if any, of these interpretations comes closest to capturing the meanings of the "Fortaleza is the blonde bride of the sun" metaphor. Metaphor is special for its generative powers to communicate a seemingly endless range of meanings, feelings, and impressions about the topic. The challenge for metaphor scholars is to provide a theoretical account of both what metaphors mean and how people arrive at their interpretations of metaphors. But can we ever really know what a metaphor means or accurately describe how people typically interpret metaphoric language?

My purpose in this article is to explore some of the dynamic complexities associated with interpreting metaphors in discourse. I argue that metaphoric meanings, and the processes by which these meanings are understood, 
are always relative to a number of intersecting factors, enough so that we cannot definitely state what a specific metaphor might mean or that all people interpret metaphoric meanings in a similar manner. However, the indeterminacy of metaphoric meaning and metaphor interpretation can still be systematically studied and theories of metaphor understanding can be created that capture important facets of human metaphor experience.

\section{COGNITIVE EFFORT IN METAPHOR INTERPRETATION}

My students' interpretations of "Fortaleza is the blonde bride of the sun" illustrate some of the complexities in the dynamics of metaphor interpretation. First, metaphor understanding requires that people know certain things about the source domain of a metaphor, which, as is the case here, can be rather complex and indeed metaphorical (e.g., "blonde bride of the sun"). People need to access their knowledge of brides, suns and blondes, as well as their stereotypical and cultural impressions of these ideas to infer what they symbolically represent. Second, people need to have sufficient time to access this information and apply it toward teasing out the varied possible interpretations of the "blonde bride of the sun" metaphoric expression.

But the task of understanding any verbal metaphor differs depending on the context, and listeners' motivations when they interpret a metaphor. Most readers of "Fortaleza is the blonde bride of the sun" when they first encounter it on an internet web site may infer positive attributes about Fortaleza (e.g., Fortaleza is a beautiful place) without going into greater detail about what the metaphor possibly means. Ordinary readers and listeners may rapidly create crude, yet satisfactory, interpretations of the metaphors they encounter in everyday speech and writing. Yet my students spent several minutes wondering about the meanings of the "Fortaleza is the blonde bride of the sun" metaphor and come up with various, but different, interpretations. Literary critics also spend extensive periods of time trying to decipher what metaphors mean (e.g., Shakespeare's "Juliet is the sun"), and sometimes write pages offering their varied interpretations. As one philosopher once aptly noted, "Dwell on a metaphor long enough, even a relatively uninteresting one, and numerous and various interpretations come to mind" (Bergmann 1979: 231). 
But what determines how long one dwells on a metaphor, or any other instance of language? One proposal for answering this question assumes that speakers aim to be optimally relevant in saying what they do (Sperber \& Wilson 1995). Optimizing relevance is a fundamental tenet of relevance theory (Sperber \& Wilson 1995). Under this "optimally relevant" view, every act of ostensive behavior, such as the production of the "Fortaleza is the blond bride of the sun" metaphor, communicates a presumption of its own optimal relevance, that is, a presumption that it will be relevant enough to warrant the addressee's attention and compatible with the communicator's own goals and preferences (the Communicative principle of relevance). Speakers design their utterances to maximize the number of cognitive effects listeners infer while minimizing the amount of cognitive effort to do so. Newly presented information is relevant in a context only when it achieves cognitive effects in that context, and other things being equal, the greater the cognitive effects, the greater the relevance.

In general, speakers balance the trade-off between maximizing cognitive effects (i.e., meanings) and minimizing the cognitive effort addressees will need to expend to recover those effects by making certain choices about both what they say and how they say it. Listeners too aim to achieve optimally relevant interpretations by again trying to maximize sufficient cognitive effects while minimizing cognitive effort. This suggests that the amount of effort put into reading "Fortaleza is the blonde bride of the sun," and the cognitive effects generated from this reading, will vary depending on the context, and the goals of the people reading this, or any other, metaphorical expression.

There is an interesting psychological consequence of this trade-off between trying to minimize cognitive effort while maximizing cognitive effects in metaphor comprehension. Consider what the speaker intends to communicate by the metaphoric phrase "Marriage is an ice box" in the following conversational exchange:

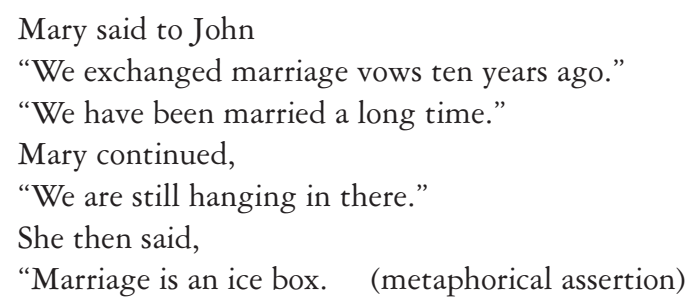


Mary's final statement conveys a declarative assertion that compares her marriage to an icebox from which a listener presumably draws a variety of inferences, such as that Mary's marriage is unemotional, confining, and perhaps lacking in sex.

Now compare the meaning of this expression when it is used in a slightly different context.

Mary said to John,

"We exchanged marriage vows ten years ago."

"We have been married a long time."

John then asked,

"Are you happy in your marriage?"

Mary then said,

"My marriage is an icebox." (metaphorical assertion + implicature)

In this situation, Mary's utterance about her marriage not only conveys certain information about her marriage, but also provides an indirect answer to John's question about whether she is happy in her marriage. Thus, Mary's final utterance conveys both a metaphorical assertion and a conversational implicature.

On the surface, "My marriage is an icebox" appears to convey more meanings in the second context than in the first by virtue of the added conversational implicature in the second case, which was set up by John's question. One reasonable expectation following this is that people should take more effort, and more time, to comprehend the metaphorical utterance in the second context than in the first. But in fact, the results of a reading time experiment, where people read stories like the above one line at a time on a computer screen, showed that this was not the case. Readers took slightly, but significantly less time to read "My marriage is an icebox," and many similar metaphors, in contexts like the second context (1403 milliseconds) than in the first type of contexts (1492 milliseconds) (Lonergan \& Gibbs, in preparation).

What explains this seemingly contradictory result that metaphors conveying conversational implicatures can take no more, or even less, time to comprehend than metaphors that do not convey implicatures? Relevance theory has a specific idea on what constrains processing, titled 
the "relevance theoretic comprehension procedure" that suggests an answer to this question.(Sperber \& Wilson 2002: 13). According to this procedure, people go through two steps understanding what an utterance means in discourse:

(a) Follow a path of least effort computing cognitive effects. Test interpretive hypotheses (e.g., disambiguations, reference resolution, implicatures, etc.) in the order of their accessibility.

(b) Stop when your expectations of relevance are satisfied.

For the above contexts, listeners' expectations of optimal relevance differ in each situation. In the context where Mary's metaphor also conveys an implicature, providing a "yes" or "no" response to the John's question the implicature comes across so strongly as to make that interpretation immediately relevant, thus short-circuiting processing of the various metaphorical meanings of "My marriage is an icebox." Thus, once listeners infer sufficient enough cognitive effects from the metaphor to promptly answer John's question, processing stops as that interpretation will satisfy the principle of optimal relevance (e.g the ostensive stimulus is relevant enough for it to be worth the addressee's effort to process it, and the ostensive stimulus is the most relevant one compatible with the communicator's abilities and preferences, Sperber \& Wilson, 1995: 270). Understanding "My marriage is an icebox" in the first context where no question is asked allows listeners to derive more metaphorical meanings in order to derive an optimally relevant interpretation in that situation. In the second context, people may derive various possible meanings of Mary's metaphor including ideas like her marriage being unemotional, never changing, unpleasant, and so on.

The important point is that listeners appear to be drawing different metaphorical inferences about "My marriage is an icebox" in the two contexts considered here. People do not necessarily create a "full" understanding of metaphoric meaning and only then derive pragmatic implications (i.e., answering yes to John's question) from this. There appears, then, to be a dynamic interaction between metaphoric meaning and pragmatic implications in people's interpretations of metaphoric language. How much of any metaphor is understood will depend on what is optimally relevant in context. Metaphoric meanings can, therefore, be short-circuted given expectations of optimal relevance. 
Relevance theory provides several suggestions about the general kinds of pragmatic purposes speakers try to achieve in discourse, which are germane to understanding the dynamic complexities of metaphor interpretation. Speakers of metaphor, just as for any other utterance, may aim to (1) strengthen an existing assumption, (2) add new information provided by a contextual implication, and (3) contradict and possibly eliminate an existing assumption. How might these different cognitive effects be manifested with metaphor? Consider the following three contexts, each of which ends with the metaphorical statement "Lawyers are sharks."

Strengthening context, Tom said to Peter:

"Lawyers support malicious people."

"They don't care about the victims."

"They just care about the money"

"Do you have anything to add, Peter?"

Peter replied:

"Lawyers are also sharks."

New information context - contextual implication

Tom said to Peter:

"Lawyers work in a court".

"They went to a law school".

"They specialize in different fields."

"Do you have anything to add, Peter?

Peter replied:

"Lawyers are also sharks."

\section{Contradiction Context}

Tom said to Peter:"Lawyers support people in need"."They care about their client's troubles." "They are not concerned with money".

"Do you have anything to add, Peter?"

Peter replied: "Lawyers are also sharks". These different contexts evoke different readings of "Lawyers are sharks." Each of these different meanings is related to some sort of metaphorical understanding of the comparison between "lawyers" and "sharks." But the pragmatic effects one draws from reading this metaphorical utterance in the three contexts nevertheless differ quite a bit (Gibbs \& Tendahl 2006). 
One set of psycholinguistic experiments showed that people took significantly longer to read the metaphors in the contradictory contexts (1939 milliseconds) than they did either the strengthening (1717 milliseconds) or contextual implications (1709 millisecond) contexts (Gibbs, Tendahl, \& Okonski, in preparation). These experimental results demonstrate how context critically determines cognitive effort and effects when interpreting metaphoric meaning. Pragmatics appears to shape the processing of the so-called "metaphoric meanings" and can limit the depth of metaphor processing in context.

A different complexity that affects assumptions of optimal relevance concerns readers' or listeners' beliefs about who speakers and writers are and what their likely communicative intentions may be. One set of experiments demonstrated that readers found metaphorical comparisons, such as 'Cigarettes are time bombs', to be more meaningful when famous 20th century poets supposedly wrote these statements, who are intentional agents, than when these same metaphors were seen as random constructions of a computer program (Gibbs, Kushner, \& Mills 1991). People also took much less time to comprehend these comparisons when they were told the poets wrote the statements. Moreover, they took longer to reject anomalous utterances (e.g., "A scalpel is a horseshoe") as 'meaningful' when the poets supposedly wrote these. Readers assume that poets have specific communicative intentions in designing their utterances, an assumption that does not hold for unintelligent computer programs. Consequently, people make a good deal more effort to try to understand anomalous phrases when poets supposedly wrote them. They more quickly rejected as 'meaningless' these same anomalous expressions when told that an unintelligent computer program wrote them, because computers are assumed to lack communicative intentions.

These findings demonstrate an important point for theories of metaphor interpretation that extra cognitive effort does not necessarily lead to additional cognitive effects. People may spend a good deal of time trying to understand a metaphor without obtaining many cognitive effects, precisely because they assume that the speaker's utterance may have been intended for relevance purposes. This explanation fits in perfectly with one of relevance theory's fundamental claims, the communicative principle of relevance, which states, "Every act of ostensive communication communicates a presumption of its own optimal relevance" (Sperber and 
Wilson 1995:260), something that experimental participants in Gibbs et al. (1991) clearly adhered to when reading the famous poets (i.e. adhering to the presumption of optimal relevance), but not when reading statements in the computer program condition (i.e. where the presumption of relevance does not appear to hold).

Understanding what any metaphor means is not simply a matter of getting to a particular metaphoric meaning, but understanding what a speaker pragmatically intends to achieve by use of that trope. Most psycholinguistics studies on metaphor understanding fail to consider these pragmatic effects by focusing on crude distinctions between literal and metaphoric meanings, and incorrectly attributing variations in processing time to constructions of those meanings (i.e., literal vs. metaphoric) without paying sufficient attention to the pragmatic goals that speakers' have in real discourse. Much greater emphasis should be placed on the precise pragmatic effects achieved by different metaphors and how particular metaphorical expressions may lead to very different pragmatic effects in context.

\section{COGNITIVE EFFECTS IN METAPHOR INTERPRETATION}

Metaphor scholars are clearly interested in the products of metaphor understanding, or what cognitive effects people take away from their experiences with metaphors in discourse. One of metaphor's great beauties is being able to quickly create a wide range of thoughts, meanings, attitudes, and emotions within listeners and readers, especially in cases of novel poetic metaphors (e.g., "Fortaleza is the blonde bride of the sun"). Psycholinguistic research also shows, however, that people can quickly infer complex meanings for even the most conventional, clichéd metaphoric expressions such as idioms and proverbs (Gibbs, 1992, 1994). For example, people appear to readily understand that an American idiom like "John blew his stack" communicates much more than simply John got angry, including inferences such as that John became angry due to internal pressure, that got angry unintentionally and did so in a violent manner.

But we still do not have a good way of empirically measuring exactly what it is that people interpret when they see or hear a metaphor. Linguists, philosophers, and literary scholars largely rely on their own intuitions to tease out what any metaphor means. Psychologists and psycholinguists, 
on the other hand, employ a variety of measures for eliciting and then examining the products of people's metaphorical experiences. For instance, one could go back and analyze the interpretations of "Fortaleza is the blonde bride of the sun" created by my university students to see if there are consistent elements that reflect underlying cognitive processes associated with metaphor processing and interpretation. Yet even here, one immediately encounters a major problem that is really fundamental to all theories of metaphor use.

If one maintains, as I have done here, that part of the dynamics associated with metaphor interpretation is that there is some trade-off between cognitive effort and cognitive effects, we need empirical measures of both cognitive effort and cognitive effects. Determining cognitive effort has been studied using various speeded tasks, such as measuring how long it take a reader to interpret a metaphor in a story context, where the length of understanding time is taken from the time a metaphor appears on a computer screen to when a person pushes a button indicating his or her comprehension of that metaphor in context. Various other measures have been created to assess metaphor comprehension effort during online language understanding (Gibbs 1994; Glucksberg, 2001).

Yet characterizing what people interpret for a metaphor is much harder to do. How do we actually count or innumerate the meanings of metaphors? Consider the stock metaphor "Some jobs are jails." There are a variety of emergent meanings that people may understand when reading this expression, including that some jobs are poorly paid, confining, stifling, unpleasant, demoralizing and so on. At the same time, reading this single metaphorical phrase may evoke varied affective reactions, including memories of bodily feelings of entrapment that one may have experienced in jobs.

The question is whether it is possible to clearly distinguish between these meanings and impressions. A psychologist may ask readers to write down their interpretations of "My job is a jail" and then count the number of meanings they express. But if a reader lists "confining" and "stifling" as part of her understandings, do these count as truly separate metaphorical meanings of the phrase "My job is a jail"? If a different reader says that this metaphor means "My job is terrible," does the term "terrible" express a particular meaning, or a more general concept that serves as an umbrella term for many other, more specific meanings for "My job is a jail" such as "confining," "stifling," and so on? 
Another problem in measuring the cognitive effects of metaphor interpretation is that different listeners and readers will produce different readings on different occasions, because information in long-term memory varies with regard to what assumptions are attached to what information (e.g., concepts, beliefs, knowledge of the author), and how readily accessible they are at any moment in time. One implication of this conclusion is that psychological accounts of figurative language experience must be situated within complex, real-world discourse dynamics. It may be impossible to state that people always experience the same thing when interpreting metaphoric meaning.

Part of the problem here is that cognitive science now recognizes that the brain/mind forms thoughts in a highly distributed manner. Consider your memory for "fork." There is no single place in our brain where we will find an entry with the word "fork" followed by a dictionary definition of what a fork is or what "fork" means. There are a number of records in our brain that correspond aspects of our past interaction with forks: their shape, the typical movement with which we use them, the hand shape and hand motion required to manipulate a fork, the result of the action, and the word that designates it in whatever many languages we know. Thus, the meanings of words are not nicely packaged and delineated in our minds, or mental lexicons.

The meanings of any individual metaphorical word, utterance, or text will be similarly complex and multidimensional in ways that cut across various cognitive, sensory, and affective boundaries. This makes it impossible to uniquely "list" or "count" the meanings of metaphors (or any other instance of language). For this reason, it is fair to conclude that metaphorical meaning is "indeterminate." But does this conclusion imply that we can never study the cognitive effort and effects in metaphor interpretation? My answer to this question is clearly no. But to adequately study metaphor interpretation, and indeed capture some of its dynamic complexities, it will require scholars to be local in their analyses and be careful in the types of generalizations they make based on the data they consider. One way of understanding these dynamic complexities is to properly acknowledge several broad factors that shape the cognitive effort and effects of metaphor interpretation. 


\section{FACTORS THAT SHAPE METAPHOR INTERPRETATION}

My suggestion is that there are at least four broad factors that underlie the dynamic complexities of metaphor interpretation: (1) the participants, (2) the understanding goal/task, (3) methods for assessing understanding, and (4) language materials. Fortunately, there is research relevant to each of these factors in regard to metaphoric language use, even if at present these findings have not been placed within a larger theoretical framework.

\section{People}

Consider just some of the ways that people differ:

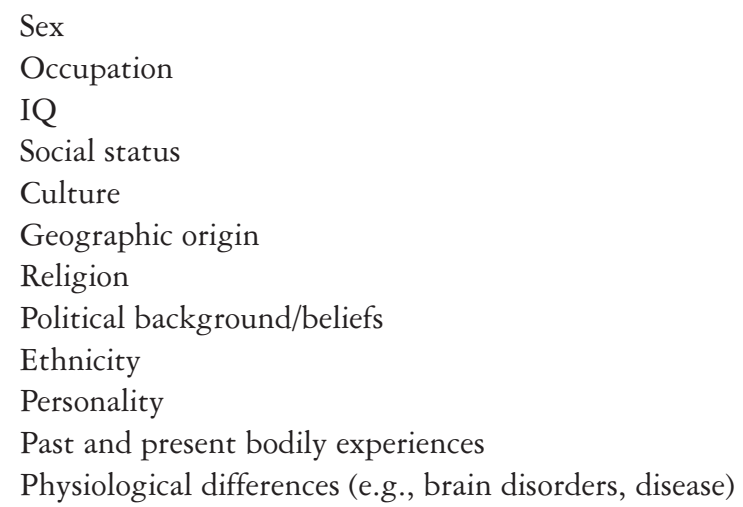

Many of these individual differences have shown to affect metaphoric language use and understanding. Let's consider just a few of these. Women produce more metaphors in talking about their own feelings (e.g., "I would feel like my heart would just jump out of my chest....") than do men (Link \& Kreuz, 2005). People in certain occupations, such as the clergy and teachers, have been shown to use metaphorical language more so than individuals in other occupations, and listeners appear to use this information in quickly determining whether a person is speaking with metaphorical intentions (Katz 2005).

People with high and low IQs differ in their performance on a task where they had to quickly judge whether metaphoric statements, like "My job is a jail” were literally false (Kazemski, Blasko, \& Dessalegu 2002). The 
results showed that metaphors were more difficult to reject as literally false compared to scrambled controls, but high IQ participants showed more interference than did participants with lower IQ. This implied that lower IQ participants experienced less activation of the metaphorical meaning that did the high IQ participants. Low IQ participants were still able to interpret the metaphorical meanings, but doing so required additional cognitive effort than was used by the high IQ participants. Not surprisingly, low IQ subjects also produced poorer quality interpretations of the metaphors than did the high IQ participants. Individuals with right-hemisphere brain damage have also long been noted to experience difficulty interpreting metaphors, compared to patients with left-hemisphere brain disorders (Winner \& Gardner 1977). Burgess and Chiarello (1996) argues that righthemisphere patients are impaired for the broader semantic activation of word meaning that is critical to interpreting metaphors, especially in cases when the context does not strongly induces a figurative reading.

Past and current embodied experiences also affect metaphor comprehension. For example, people's previous bodily experiences of hunger partly predicts their use and understanding of metaphorical expressions about difference forms of desire, as seen in statements like "I hunger for fame" or "I craved her affection" (Lima, Gibbs \& Françozo , 2001). In another series of studies on metaphorical talk about time, students waiting in line at a café were given the statement "Next Wednesday's meeting has been moved forward two days" and then asked "What day is the meeting that has been rescheduled?" (Borodistky \& Ramscar 2002). Students who were farther along in the line (i.e., who had thus very recently experienced more forward spatial motion) were more likely to say that the meeting had been moved to Friday. These results suggest how ongoing sensorimotor experience has an influence on people's comprehension of metaphorical statements about time. Finally, Wilson and Gibbs (2007) showed that people's speeded comprehension of metaphorical phrases like "grasp the concept" are facilitated when they first make, or imagine making, in this case, a grasping movement.

Complementary to the findings from psycholinguistics, many cognitive linguistic analyses of metaphor in different environments and cultures demonstrate that certain metaphorical conceptualizations, such as those for emotion and illness, depend on variation in "experiential focus" (Kövecses 2005). People in different geographical and social contexts are attuned 
to different aspects of their bodily experience, which partly motivates differences in the ways that people express themselves metaphorically about certain topics.

Overall, there are many cognitive, physiological, and cultural differences between people that affect both when and how metaphors are produced and interpreted.

\section{UNDERSTANDING GOAL/TASK}

Interpreting metaphor is not a singular, monolithic activity but differs depending on a person's goals or the task her or she has undertaken. Consider some of the understanding goals that people may have when faced with metaphoric language:

\footnotetext{
Quick comprehension in conversation/reading

Explicit recognition of metaphor

Reflective interpretation in reading

Solving problems/Making decisions

Arguments/Persuasion

Memory

Appreciation/Explicit aesthetic judgments
}

These different facets of "understanding" are not completely separate, but overlap in complex ways. For instance, metaphor appreciation depends on some earlier comprehension of a metaphor. Comprehension is also clearly a part of slower interpretation processes. At the same time, people may recognize that a series of words is a metaphor, for instance, without necessarily understanding many, if any, of its metaphorical meanings. People can ordinarily comprehend metaphors without any conscious or tacit recognition that they have encountered a "metaphor." In general, these different temporal moments of understanding have complex relations with one another, and it is important not to assume that the experimental study of one aspect (e.g., appreciation) necessarily informs the theoretical analysis of another part (e.g., comprehension) (Gibbs 1994). For example, studies show that people better appreciate metaphors in poems when they are first recognized these phrases as metaphors than if they were not first explicitly recognized (Gibbs 2004). 
As I argued earlier, people who quickly read "Fortaleza is the blonde bride of the sun" create different, usually simpler interpretations than do individuals who deliberate on the possible, varied meanings that this metaphor can have. Much work in psycholinguistics illustrates that the task that a person has in trying to understand a metaphor will give rise to rather different meaning products (Gibbs 1994). Psychologists will often explicitly instruct experimental participants on how to read a metaphor in some context (e.g., read and comprehend as fast as possible, read and write out as many of the meanings you can think of, read and give ratings of how apt a metaphor is, etc). On the other hand, most of us, as we are moving about in the world, may not have a single goal in mind when encountering a metaphor (e.g., comprehend, remember, be persuaded by), but hear or read metaphors with either multiple goals in mind (e.g., comprehend and learn) or we let the metaphor itself, and the context in which we see it, to lead us to understand it in complex ways (e.g., my looking up information about Fortaleza, seeing the "blonde bridge of the sun" metaphor, recognize it explicitly as a metaphor, appreciate it and so on).

My point is that our understanding of metaphor does not happen from a neutral viewpoint and that the very process of understanding a metaphor may lead us to engage in several overlapping processes as we determine its possible cognitive effects.

\section{METHODS FOR ASSESSING METAPHOR UNDERSTANDING}

Given that people often have different goals when understanding metaphor, what is the best method for assessing metaphor interpretation? I earlier briefly explored people's metaphor understanding by asking a small group of university students to read and write out the possible meanings of "Fortaleza is the blonde bride of the sun." This type of introspective method is somewhat typical of what most linguists, philosophers, and literary scholars engage in when they try to interpret the meanings or metaphors, and from this, propose theories of metaphor understanding.

But consider some of the ways that psychologists have examined people's ability to understand metaphoric language: 


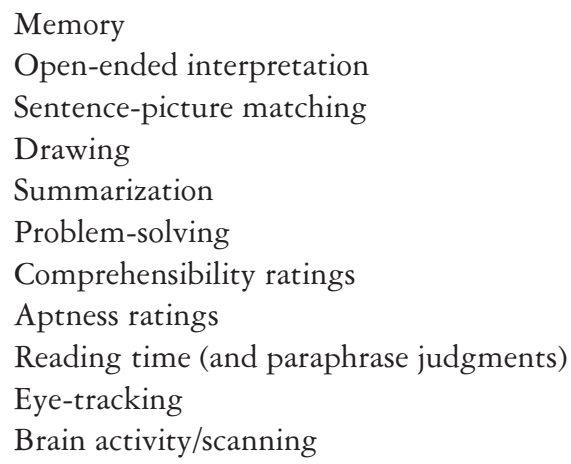

The best method for assessing metaphor interpretation has always been a significant source of concern in psycholinguistics (Gibbs 1994; Giora 2002; Glucksberg 2001). Tasks that have used off-line measures (e.g., rating studies, judgments of metaphor aptness, memory tasks) as indicators of metaphor comprehension have often been criticized for their inability to distinguish processes that might take place during immediate reading or hearing in the comprehension process versus those that may only occur later in the processing stream where more reflective, idiosyncratic interpretations may be created. Reading time measures were long considered superior because they could use overall reading time as a more precise, and presumably outside of subjective control, indicator of on-line processing-relying upon the assumption that, all else being equal, longer reading times indicated greater processing. But reading time studies also differ in their specific task requirements. Some experiments asked participants to simply read individual sentences in a story, and push a button as soon as the expression on the computer screen has been understood. Yet other studies ask people to sometimes read an expression, such as a metaphoric remark, and make a speeded judgment as to whether it fits within the preceding story context. As it turns out, judgments of appropriateness or relatedness often result in longer comprehension times for metaphoric expressions compared to literal ones (Temple \& Honeck 1997). But metaphoric and literal expressions can be read equally fast when only simple comprehension time is measured (Gibbs 1994). Thus, the precise task used leads to different results with very different theoretical implications.

My point here is, once again, that there is no neutral method for assessing metaphor understanding. Each method is able, in different ways, 
to tap into different aspects of the unconscious and conscious processes that can occur when people hear or read metaphors in discourse context. In the past, scholars have mistakenly made theoretical claims about fast processing from slower, and consciously-held, interpretations and appreciations, while psycholinguists, again, have mostly neglected the rigorous study of cognitive effects, or the products of metaphoric language understanding. Yet once more, paying systematic attention to cognitive effects, both those that arise immediately during fast comprehension, and those that emerge more slowly during reading (and re-reading!) is critical to creating more comprehensive theories of metaphoric language use in different real world, communicative contexts.

\section{LANGUAGE MATERIALS}

Finally, consider some of the factors associated with language-related differences that may shape the dynamic interpretation of metaphor.

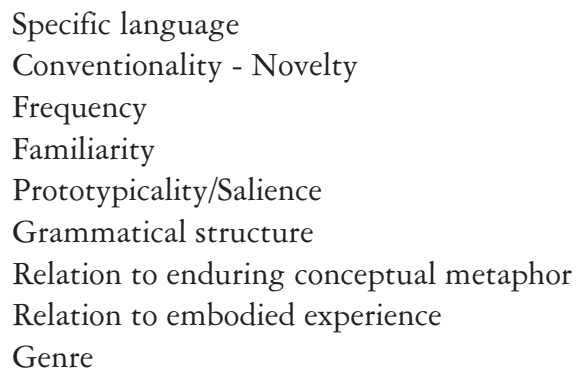

The specific language spoken clearly determines whether a person uses metaphoric language, and what kind of metaphor, in referring to particular ideas and events. For example, English and Spanish have different metaphoric means for expressing metaphorical ideas about path, manner, and end-result conceptualizations. Different languages verbally manifest in slightly different ways the same underlying conceptual metaphor, such as the different ways that Hungarian and English instantiate the LOVE RELATIONSHIP IS A JOURNEY metaphor (Kövecses 2005). Different cultures may also place varying values on different entities and events. For instance, horses play different roles in England and Spain, which provides a reason for why horses serve as very different metaphorical vehicles in 
English than in Spanish (Deignan 2003). Psycholinguistic research suggests that people's metaphoric conceptualization about time and temporal events differ depending on the language spoken, particularly in the case of Mandarin and English (Borodistky 2001).

Various experimental studies have also shown that conventional and novel metaphors are understood differently (Bowdle \& Gentner, 2002; Katz, 2005), and that the salience of metaphoric meaning for any utterance differs depending on a variety of factors its grammatical form, frequency in the language, appropriateness to the specific context, and appropriateness for the speaker (Colston 2005; Giora 2002). Not surprisingly, the ease with which a person interprets a metaphor, and determines simple or rich metaphoric meanings, depends on the discourse context in which it is heard or seen (Gibbs 1994). Thus, contexts that describe topics in metaphorical ways make it easier to infer subsequent metaphoric utterances when the underlying conceptual metaphors are similar (Albritton, McKoon, \& Gerrig 1995), and more difficult to process when a new metaphorical utterance is based on a different conceptual metaphor (Langston 2002). Although the vast amount of experimental work on metaphor comprehension examines what people have understood, and the speed with which they do so, of a single utterance after a non-figurative context, it is evident that different metaphoric contexts, and previously spoken figurative (i.e., metaphoric and metonymic) utterances, have a strong effect of online metaphor processing, as shown by the results of Lonergan and Gibbs (in preparation) and Gibbs et al. (in preparation), discussed above. Although there has no been very much experimental work related to the effect of genre on metaphor understanding, it is often proposed that people will interpret metaphors to varying degrees of depth depending on the genre (Goatly 1998; Steen, 2007) with genre leading people to have different degrees of motivation in how they approach the task of metaphor understanding.

Finally, the degree to which a particular metaphoric expression is related to a pre-existing conceptual metaphor, will also shape the cognitive effort and effects involved in metaphor interpretation (Gibbs 1994).

Overall, when we talk about how metaphors are understood we must consider the specific linguistic qualities and linguistic/cultural contexts in which metaphors are created and used. 


\section{Conclusion}

My main argument in this article is that a wide variety of factors influence the cognitive effort and cognitive effects associated with metaphor interpretation. Understanding metaphor is not a single type of activity, and metaphoric meanings are inherently indeterminate, with both of these shaped by numerous personal, contextual, and linguistics factors. These variables interact with one another in complex, dynamic, often nonlinear, ways such that it is virtually impossible to provide a single, default theory on what metaphors mean or how metaphors they are understood. As much as metaphor scholars sometimes try to reduce or eliminate some of these factors from their own analyses of metaphor, or from their experimental tests of metaphor understanding, we must recognize the inherent embodied, embedded nature of thought and language and strive toward situating theories of metaphor in real world contexts.

This conclusion may be disappointing to some, or seem overly pessimistic about any attempt to create a comprehensive theory of metaphor. A scholar may be interested in some particular variable, such as any of those noted in the previous section, and simply wish to focus their own empirical work on studying the effect of that variable on metaphor use and meaning. Frankly, there is absolutely nothing wrong with doing this, and indeed we have learned a tremendous amount about the variety of influences on metaphor interpretation from such studies. But scholars too often end up privileging their own variables of interest (i.e., personal, cognitive, linguistic, cultural, pragmatic) in their theoretical accounts of metaphor, sometimes openly downplaying other relevant factors and the theories that are created to account for these other variables.

What is critically needed, however, is further exploration of some of the joint interaction of the factors that shape metaphor use, with an eye toward mapping out all of the dynamics related to the cognitive effort and effects of metaphor use. This will require a greater openness toward methods and theoretical perspectives that often differ from the ones that each of us personally embraces in our own work as metaphor scholars. Yet the pay-off of this greater diversity in the ways that each one of us approaches the topics of metaphorical meaning and interpretation will have tremendous benefits in really, again, situating the study of metaphor into the complex ecological niches in which it is seen. In this way, my appeal is for a better appreciation 
of the complexities of metaphorical meaning and understanding, and the relations between meaning and understanding, which will enable us to see the true beauty of metaphor in language, thought, and culture.

Recebido em novembro de 2009

Aprovado em abril de 2010

E-mail: gibbs@ucsc.edu

\section{REFERENCES}

Allbritton, D., McKoon, G., \& Gerrig, R. 1995. Metaphor-based schemas and text representations: Making connections through conceptual metaphors. Journal of Experimental Psychology: Learning, Memory, E Cognition, 21: 612-625.

Bergmann, M. 1979. Metaphor and formal semantics. Poetics, 8: 213-230.

Boroditsky, L. 2001. Does language shape thought? English and Mandarin speakers' conceptions of time. Cognitive Psychology, 43: 1-22.

Boroditsky, L. \& Ramscar, M. 2002. The roles of body and mind in abstract thought. Psychological Science, 13: 185-189.

Bowdle, B. \& Gentner, D. 2005. The career of metaphor. Psychological Review, 112: 193-216.

Burgess, C. \& Chiarello, C. 1994. The neurocognitive mechanisms underlying metaphor comprehension and other figurative language. Metaphor and Symbol, 11: 67-84.

Colston, H. 2005. Social and cultural influences on figurative and indirect language In H. Colston and A. Katz (Eds.) Figurative language comprehension: Social and cultural factors (pp. 99-130). Mahwah, NJ: Erlbaum.

Deignan, A. 2003. Metaphorical expressions and culture: an indirect link. Metaphor and Symbol, 18: 255-272.

Gibbs, R. 1992. What do idioms really mean? Journal of Memory and Language, 31: 485-506.

. 1994. The poetics of mind: Figurative thought, language, and understanding. New York: Cambridge University Press.

. 2002. Identifying and appreciating poetic metaphor. Journal of Literary Semantics, 31: 101-112.

Gibbs, R., Kushner, J. \& Mills, R. 1991. Authorial intentions and metaphor comprehension. Journal of Psycholinguistic Research, 20: 11-30. 
Gibbs, R., Tendahl, M., \& Okonski, L. (in preparation). How to do things with metaphor in discourse.

Giora, R. 2002. On our minds: Salience, context, and figurative language. New York: Oxford University Press.

Glucksberg, S. 2001. Understanding figurative language: From metaphors to idioms. New York: Oxford University Press.

Goatly, A. 1998. The language of metaphor. London: Routledge.

KaTZ, A. 2005. Discourse and sociological factors in understanding nonliteral discourse. In H. Colston and A. Katz (Eds.) Figurative language comprehension: Social and cultural factors, 183-208. Mahwah, NJ: Erlbaum.

Kazmerski, V., Blasko, D. \& Dessalegn, B. 2002. Erp and Behavioral evidence of individual differences in metaphor comprehension. Memory and Cognition, 31: 673-689.

Kovecses, Z. 2005. Metaphor in culture: Universality and variation. New York: Cambridge University Press.

2006. Language, mind, and culture: A practical introduction. New York: Oxford University Press.

KreUZ, R., \& Link, K. 2005. Do men and women differ in their use of nonliteral language when they talk about emotion? In H. Colston and A. KATz (Eds.) Figurative language comprehension: Social and cultural factors, 153-182. Mahwah, NJ: Erlbaum.

LAngston, W. 2002. Violating orientational metaphors slows reading. Discourse Processes, 34: 281-310.

Lima, P., Gibbs, R. \& Françozo, E. 2001. Emergencia e natureza da metaphora primaria: Desejar e ter fome. Cadernos de Estudos Linguisticos, 40: 107-140.

Lonergan, J., \& GibBs, R. (in preparation). How relevance expectations determine what metaphorical meanings are understood.

Sperber, D., \& Wilson, D. 1995. Relevance: Cognition and communication. New York: Blackwell.

Steen, G. 2007. Finding metaphor in grammar and usage. Amsterdam: Benjamins.

Temple, J., \& Honeck, R. 1999. Proverb comprehension: The primacy of literal meaning. Journal of Psycholinguistic Research, 28: 41-70.

Wilson, N. \& GibBs, R. 2007. Real and imagined body movement primes metaphor comprehension. Cognitive Science, 31: 721-731.

WINNER, E. \& GARDNER, H. 1977. The comprehension of metaphor in brain-damaged patients. Brain, 100: 717-729. 